\title{
Investigating Pesticide Use and Management in King Orange (Citrus nobilis) Farming in Vung Liem District, Vinh Long Province, Vietnam
}

\author{
Nguyen Thanh Giao
}

College of Environment and Natural Resources, Can Tho University, Vietnam ntgiao@ctu.edu.vn

Received: 01 Nov 2020; Received in revised form: 11 Jan 2021; Accepted: 29 Jan 2021; Available online: 16 Feb 2021 (C)2021 The Author(s). Published by Infogain Publication. This is an open access article under the CC BY license (https://creativecommons.org/licenses/by/4.0/).

\begin{abstract}
The study was conducted to evaluate the current situation of pesticide use on the model of growing king orange (Citrus nobilis) in Hieu Nghia commune, Vung Liem district, Vinh Long province, Vietnam thereby assessing the potential effects of the pesticide use on health and the environment by direct interviewing 60 farmers growing king orange. Information on the potential effects of the pesticide use is retrieved from available scientific databases of chemical toxicity. The results showed that $100 \%$ of the households use pesticides during cultivating king orange in which $60 \%$ of the farmers using chemical pesticides, $36.7 \%$ using biological ingredients, $36.7 \%$ and $3.3 \%$ using pesticides with unknown sources. The interview results showed that the households used 6 pesticides with toxic group I; 53 pesticides with toxic group II; 22 pesticides with toxic group III and 40 pesticides with toxic group IV. There were $60 \%$ of the households used pesticide dosage according to the instructions on the package; $26.7 \%$ of the households used more than recommended dosage and 13.3\% households used less than recommended dosage. The number of the farmers with clear understanding of the harmful effects of plant protection chemicals accounted for 5.0\%, with knowledge accounting for $48.3 \%$, with little knowledge of $31.7 \%$ and ignorance at $15 \%$. Regarding the methods of handling pesticides packages after use, there were $45 \%$ of the farmers treated the wastes by disposing of in the fields, $30 \%$ selling to vendors and $25 \%$ burning the wastes. With the current knowledge and practice of using and managing pesticides, the risk to the environment and the health of the people is very serious. Health, environment and agriculture agencies should take measures to support people in protecting health, managing wastes generated from pesticides use to reduce risks to health and the environment.
\end{abstract}

Keywords - king orange, active ingredients, environment, health, Vung Liem, Vinh Long.

\section{INTRODUCTION}

The Mekong River Delta (Mekong Delta) has about 307,000 ha of fruit trees, giving an annual yield of about 3.5 million tons of fruit; of which over 120,000 hectares were planted with special crops such as durian, Hoa Loc mango, Lo Ren milk fruit, Nam Roi pomelo, green skin pomelo, king orange, rambutan. Vinh Long is located between Tien River and Hau River, and also belongs to the arterial traffic route connecting the Southeast region with the Mekong Delta, so most of the province's urban districts are next to the large waterway - land transport system, relatively close distance, on average $18 \mathrm{~km}$ and the city furthest from the center of the province only about $45 \mathrm{~km}$. The potential for developing peri-urban agriculture is huge, equivalent to about $60 \%$ of the province's agricultural land. King orange (Citrus nobilis) is one of the main fruit trees of our country, grown in Vinh Long, Hau Giang and Soc Trang provinces. Particularly in Vinh Long, king oranges have been grown for a long time due to high economic efficiency. In recent years, many households have converted their economically inefficient rice land to cultivated king oranges. The area of cultivated 
king oranges in Vinh Long province as of 2018 was 9,804 hectares, with an output of 105,022 tons/year, concentrated in Tra On, Tam Binh, Vung Liem districts. Vinh Long province has nearly 8,000 hectares of cultivated king oranges. This is a specialty fruit tree with high economic efficiency, planned by the provincial agriculture sector into specialized farming areas. Hieu Nghia Commune, Vung Liem District, Vinh Long Province is considered a golden land for growing king oranges because the soil is quite suitable, the tree grows well, and the yield is high. The total area of king oranges on field land in Hieu Nghia commune (Vung Liem) is now more than 371 ha, accounting for the most out of 502 ha of cultivated oranges in 9 communes with king orange in the district's field land (Department of Agriculture and Rural Development in Vung Liem district, 2019).

Recently, in addition to farming techniques, farmers need to manage pests and diseases on king orange to protect the yield and quality of king orange. Pests and diseases often cause very heavy harm, losing commercial value of the fruit and reducing yield. Thus, it reduces profits for growers of king orange. Currently, farmers who grow king orange tend to use more plant protection chemicals. There have been many studies on the use of pesticides on rice cultivation (Toan, 2011) and vegetable cultivation (Nga and Viet, 2010; Chau et al., 2019) and showed the uses of pesticides can pollute water sources (Binh, 2008; Hoai et al., 2011; Nhan, 2018). Former study by Cong et al. (2008) showed that the presence of pesticides in water can affect fish and even human health (Margni et al., 2002). Up to now, very little information on the current status of pesticide use on the king orange model has been reported. The study was conducted to investigate the current status of pesticide use on the king orange growing model in Hieu Nghia commune, Vung Liem district, Vinh Long province, thereby assessing potential impacts on the environment and health. of people cultivating king oranges.

\section{MATERIALS AND METHODS}

Data in this study were collected through field surveys and interviews with 60 king orange farmers in Vung Liem district, Vinh Long province. The questionnaire was designed in a semi-structured form to collect information about pesticides types, dosage, frequency, and understanding of the harmful effects of pesticide uses, and methods of handling the pesticide packages after use. Potential effects of pesticides on the environment and health are assessed through the type of pesticides used, the dosage, frequency, and method of treatment of the pesticide wastes after use. The effects of pesticides were also assessed using the toxicological information of the active substance found to the organism. On the basis of analysis of the current situation, a number of recommendations will be proposed to minimize the harmful effects of pesticides use on the environment and humans.

\section{RESULTS AND DISCUSSION}

\subsection{General information of the interviewees}

Results of interviewing 60 households of king orange farming showed that $73.35 \%$ of whom were male and $26.7 \%$ were female were of working age of $30-50$ years old. There were $100 \%$ of the main labor force in this household is male. These men are the ones directly involved in the cultivation and use of plant protection pesticides. The education levels of people interviewed with primary, secondary, high-school and college degrees were $56.7 \%, 25 \%, 15 \%$, and $3.3 \%$, respectively. No interviewee was illiterate or had a university degree. The number of people residing in the study area for more than 5 years accounted for $93.3 \%$ while the number of people residing under 5 years was $6.7 \%$. Through the interview results, it showed that $33.3 \%$ of the households have cultivated land area over $5000-10,000 \mathrm{~m}^{2} ; 26.7 \%$ of the households have cultivated land area from 1,000-5,000 $\mathrm{m}^{2}$. According to the interview results, $100 \%$ of the households have main income source from growing king oranges. In addition, local people earn additional income from other occupations, for example $65 \%$ grow vegetables $(65 \%)$, livestock $(17 \%)$, freelance $(10 \%)$, and civil servants and small businesses $(8.3 \%)$. The number of interviewees who have experience growing king oranges for more than 10 years, 5-10 years, less than 5 years and just started growing king oranges were $18.3 \%, 46.7 \%, 21.7 \%$ and $13.3 \%$, respectively.

\subsection{Current status of pesticide use in cultivation of king orange farming model}

The results showed that cultivating oranges have to use pesticides continuously to maintain the yield and quality of king orange. If farmers do not use pesticides, the tree would be susceptible to disease, the fruit would significantly fall, grow slowly, the orange appearance would not be beautiful and thus, influencing productivity and profitability. There were $60 \%$ of the households using chemical pesticides to prevent and treat pests and diseases for king orange trees and $36.7 \%$ of the households use biological pesticides. The study results also showed that $60 \%$ of the households used pesticide doses according to the instructions; $26.7 \%$ of the households used more than the dosage specified in the instructions for using pesticides and $13.3 \%$ of the households used less than the dosage 
specified in the instructions for using pesticides. The number of sprays was from 2 to 6 times per crop. The results of the study showed that there were currently 120 commercial names of pesticides with 73 active ingredients used. There were 6 types of pesticides belonging to group I; 53 pesticides of toxic group II; 22 pesticides in toxic group III and 40 pesticides in toxic group IV. The following information regarding toxicity of active ingredients found in the king orange farming model could indicate that the pesticides residuals could have huge impact on the environment and human health.

\subsubsection{Acephate}

Acephate has moderate acute toxicity in mammals. Evidence of carcinogenicity is limited to liver tumors that occurred in rats fed high doses of acephate over several months, and U.S. EPA considers acephate to be a possible human carcinogen (U.S.EPA, 2012). Humans and animals absorb acephate into the body quickly when it is eaten, breathed in, or gets on the skin. In animal studies, acephate was absorbed into the blood and went to skin, liver, kidneys, and heart.In humans and other mammals, about three quarters of the acephate moves through the body unchanged. Some is broken down into smaller chemicals, and a very small amount converts to methamidophos. In rats, most acephate was cleared through the urine, with small amounts cleared through the feces or exhaled breath. Acephate clears the body quickly; less than one percent of the acephate remained in rats three days after eating it.

\subsubsection{Chlorpyrifos Ethyl}

Chlorpyrifos is an organophosphate pesticide used on crops, animals, and buildings, and in other settings, to kill a number of pests, including insects and worms. It acts on the nervous systems of insects by inhibiting the acetylcholinesterase enzyme. Chlorpyrifos was patented in 1966 by Dow Chemical Company. Chlorpyrifos is considered moderately hazardous to humans by the World Health Organization based on its acute toxicity. Exposure surpassing recommended levels has been linked to neurological effects, persistent developmental disorders, and autoimmune disorders. Exposure during pregnancy may harm the mental development of children, and most home uses of chlorpyrifos were banned in the U.S. in 2001.In agriculture, it is one of the most widely used organophosphate insecticides in the United States, and before being phased out for residential use it was one of the most used residential insecticides. For acute effects, the World Health Organization classifies chlorpyrifos as Class II: moderately hazardous. The oral LD50 in experimental animals is 32 to $1000 \mathrm{mg} / \mathrm{kg}$. The dermal LD50 in rats is greater than $2000 \mathrm{mg} / \mathrm{kg}$ and 1000 to $2000 \mathrm{mg} / \mathrm{kg}$ in rabbits. The 4-hour inhalation LC50 for chlorpyrifos in rats is greater than $200 \mathrm{mg} / \mathrm{m} 3$. Acute poisoning results mainly from interference with the acetylcholine neurotransmission pathway, leading to a range of neuromuscular symptoms. Relatively mild poisoning can result in eye watering, increased saliva and sweating, nausea and headache. Intermediate exposure may lead to muscle spasms or weakness, vomiting or diarrhea and impaired vision. Symptoms of severe poisoning include seizures, unconsciousness, paralysis, and suffocation from lung failure.

Among freshwater aquatic organisms, crustaceans and insects appear to be more sensitive to acute exposure than are fish. Aquatic insects and animals appear to absorb chlorpyrifos directly from water rather than ingesting it with their diet or through sediment exposure. Acute exposure to chlorpyrifos can be toxic to bees, with an oral LD50 of $360 \mathrm{ng} / \mathrm{bee}$ and a contact LD50 of $70 \mathrm{ng} / \mathrm{bee}$. Risk assessments have primarily considered acute exposure, but more recently researchers have begun to investigate the effects of chronic, low-level exposure through residue in pollen and components of bee hives. A review of US studies, several European countries, Brazil and India found chlorpyrifos in nearly $15 \%$ of hive pollen samples and just over $20 \%$ of honey samples. Because of its high toxicity and prevalence in pollen and honey, bees are considered to have higher risk from chlorpyrifos exposure via their diet than from many other pesticides.

\subsubsection{Diazinon}

Overall, diazinon is fairly low in toxicity when inhaled, ingested or when it gets on the skin, so minor exposures are not likely to cause severe symptoms. However, small exposures to diazinon can cause mild skin or eye irritation. Diazinon generates high acute toxicity to a wide variety of aquatic organisms, leading to a wide range of sublethal biochemical effects, damage to specific target organs and tissues, and adverse ecological impacts. The toxicity of diazinon has extensively studied in fish and crustaceans, and it has been reported to be moderately toxic to early life stages of zebrafish. The $96 \mathrm{~h} \mathrm{LC50}$ values ranging from 0.32 to $1.53 \mathrm{mg} / \mathrm{L}$ for larval and from 2.2 to $10.3 \mathrm{mg} / \mathrm{L}$ for adult of several fish have already been recorded.

\subsubsection{Abamectin}

Toxicity of abamectin is oral but there are some contact activities. Intoxication manifestations include mydriasis, vomiting, tremor, seizure, partial ptosis, confusion, and coma. Mild intoxications manifest symptoms such as nausea, vomiting, diarrhea, and weakness.As all macrocyclic lactones, abamectin acts as 
agonist of the GABA (gamma-aminobutyric acid) neurotransmitter in nerve cells and also binds to glutamategated chloride channels in nerve and muscle cells of invertebrates. In both cases it blocks the transmission of neuronal signals of the parasites, which are paralyzed and expelled out of the body, or they starve. It also affects the reproduction of some parasites by diminishing oviposition or inducing an abnormal oogenesis. In mammals the GABA receptors occur only in the central nervous system (CNS), i.e., in the brain and the spinal cord. But mammals have a so-called blood-brain barrier that prevents microscopic objects and large molecules to get into the brain. Consequently, macrocyclic lactones are much less toxic to mammals than to parasites without such a barrier, which allows quite high safety margins for use on livestock and pets. A notable exception to this is dog breeds that carry the MDR-1 gene defect.

\subsubsection{Trichlorfon}

Trichlorfon is moderately to highly toxic to birds, and highly toxic to fish and aquatic invertebrates. Toxicity varies considerably depending on temperature, $\mathrm{pH}$ and water hardness. As a general rule, toxicity increases with temperature and $\mathrm{pH}$. Trichlorfon is a synthetic organochlorophosphate compound and organophosphate acetylcholinesterase inhibitor that is used as a pesticide. It is characterized as a white crystalline or colorless to yellow or pink waxy solid, and exposure occurs by inhalation, ingestion, or contact. Marketed since the 1950s, trichlorfon is used to protect field and fruit crops, to control forest insects, and to control internal and external parasites in domestic and farm animals. Trichlorfon, formulated as metrifonate, has also been used for the pharmacological treatment of Schistosoma haematobium in millions of patients. The compound is under investigation as a treatment for Alzheimer's disease. A review of environmental levels and human exposure concentrates on the significance of residues detected in crops, the milk of treated cows, and other food items as possible sources of exposure for the general public. Noting that detected levels are far below the established acceptable daily intake, the report concludes that trichlorfon does not constitute a health hazard for the general population. Concerning effects on environmental organisms, the report cites evidence that trichlorfon is moderately toxic for fish and birds, and moderately to highly toxic for aquatic arthropods, supporting the conclusion that this insecticide should never be sprayed over water bodies or streams.

\subsubsection{Fenitrothion}

The data provided by Sumitomo outlined the toxicology (acute, irritation and sensitization and sub-acute to chronic), mutagenicity and ecotoxicological profile ofthe fenitrothion technical material.Acute toxicity was low in Rats, Rabbits, Guinea Pigs, in both males and females in general toxicity and neurotoxicity terms, as shown by the $\mathrm{LD}_{50}, \mathrm{LC}_{50}$, NOELs and NOAELs. The Hershberger assay in Rats showed no anti-androgenicity or androgenicity. Fenitrothion is unlikely to pose a carcinogenic risk to humans. Fenitrothion was not genotoxic in a range of studies in vitro and in vivo. Fenitrothion is not persistent in soil and leaching is not significant. Therefore there is negligible risk to following crops or of groundwater contamination. Volatilization is a significant dissipative process in the environment although, once in the vapourphase, fenitrothion is shortlived. Transport to surface water via spray drift poses a risk to aquatic species, although the duration of exposure is brief because fenitrothion dissipates in microbially active natural water systems with a half-life ofless than one week. The compound will also tend to migrate to sediment. Health risks for avian and mammalian species following the consumption of treated vegetation, grain and contaminated insects are likely to be low. The low longterm risk to insectivorous species and birds grazing on treated grassland is not likely to arise due to:(i) the high acute toxicity of fenitrothion to insects, preventing residue build-up in this food source; (ii) the generally low persistence of fenitrothion in the environment; and(iii) the rapid decline of residues in species forming the diet. Aquatic organisms (fish and invertebrates) are potentially at risk, especially in the event of overspray to static water bodies. However buffer zones appropriate to eachcrop and monitoring wind direction to prevent spray drift should ensure that aqueous concentrations remain below the environmentally acceptable concentrations even inthe event of multiple applications. Although fenitrothion is fatsoluble, the rates of biotransformation and excretion of metabolites largely mitigate bioconcentration. Label warnings are intended to minimise the risks to fish. The risks to algal species, earthworms, soil micro-organisms and sewage bacteria

are considered to be low, even in worst-case scenarios, without taking into consideration the rapid dissipation processes that occur in the environment. Fenitrothion is extremely toxic to honeybees and highly toxic to nontarget arthropods. However, it does not have growth inhibitory activity and the effects of treatment are relatively short-lived. Most beneficial insect populations would recover quite rapidly. Label warnings are intended to minimise the risks to honeybees.

Soil microbiological processes are generally unaffected by use of fenitrothion on agricultural land. It is used in agriculture and for public health use. An 
acceptable daily intake (ADI) of $0-0.005 \mathrm{mg} / \mathrm{kg}$ body weight was established in2000. The IPCS hazard classification of fenitrothion is: moderately hazardous, class II.

\subsubsection{Mancozeb}

Mancozeb (MCZ) is one of the most used fungicides worldwide, despite its ancient use and toxicity demonstrated in different taxa. Its primary mechanism of toxicity is via skin contact, leading to contact dermatitis and dermal sensitization. Mancozeb has also been shown to have teratogenic and reproductive effects. Mancozeb exposure also alters the reproductive and endocrine structures, leading to decreased fertility. The potential of mancozeb to induce chromosomal damage in somatic cells has been investigated in four micronucleus tests in rats and mice and two cytogenetics studies in rats and mice. The toxicity profiles for lethal and sublethal effects were performed. At all exposure times, MCZ was more toxic to embryos, for instance, NOEC $504 \mathrm{~h}$ were 0.01 and 0.05 mg MCZ/L for embryos and larvae, respectively. Thus, embryo sensitivity was 5-fold higher than larvae. A Teratogenic Index of 14 indicated the significant teratogenic potential of this fungicide. Among sublethal effects, embryos exhibited a wide range of abnormalities with high incidence.

\subsubsection{Glyphosate}

Glyphosate is a widely used herbicide. Glyphosate is one of the most widely used herbicides with applications in agriculture, forestry, industrial weed control, lawn, garden, and aquatic environments. Sites with the largest glyphosate use include soybeans, field corn, pasture and hay. It can cause gastrointestinal corrosive symptoms and due to the surfactant, that is present a severe metabolic acidosis, hyperkaliemia and cardiovascular collapse can occur. The toxicity of glyphosate is largely due to the surfactant and other coformulants. Glyphosate is low in toxicity to rats when ingested. The acute oral LD50 in rats is greater than 4320 $\mathrm{mg} / \mathrm{kg}$. Glyphosate is low in toxicity to rabbits when applied to the skin. The acute dermal LD50 in rabbits is greater than $2 \mathrm{~g} / \mathrm{kg}$. Glyphosate is low in toxicity for eye irritation and very low in toxicity for dermal irritation. In studies with glyphosate manufacturing use products, researchers observed mild eye irritation in rabbits that cleared in seven days. Glyphosate is very low in toxicity to rats when inhaled. The acute inhalation LC50 in rats is greater than $4.43 \mathrm{mg} / \mathrm{L}$ based on a 4-hour, nose-only inhalation study.

\subsubsection{Zinc Phosphide}

Zinc phosphide has been used widely as a rodenticide. Upon ingestion, it gets converted to phosphine gas in the body, which is subsequently absorbed into the bloodstream through the stomach and the intestines and gets captured by the liver and the lungs. Phosphine gas produces various metabolic and nonmetabolic toxic effects. Clinical symptoms are circulatory collapse, hypotension, shock symptoms, myocarditis, pericarditis, acute pulmonary edema, and congestive heart failure.

\subsection{Current status of pesticide packaging and bottles management after use in the study area}

The interviewing results showed that there were $45 \%$ of the households that treated pesticide bottles and packaging after use by immediately discarding in the fields. As previously discussed, the pesticides are high toxic therefore the indiscriminate disposal of pesticide packaging and bottles after use in the garden could result in several negative consequences, for example, directly affecting the health of users and the whole community and environmental pollution. There were $30 \%$ of the households handled pesticide bottle and packaging after use by selling, whereas there were $25 \%$ of the households treated pesticide bottles and packaging after use by burning. The collection and handling of pesticides bottles and packaging after use were improper. Several households bury or burn the bottles and packaging of pesticides after use at the same time with domestic wastes. This could lead to seriously affect the air, soil, water environment and especially the health of the people. The indiscriminate discharge of pesticides in the environment could pose a great threat to surrounding environment and human health. More than $65 \%$ of the respondents confirmed that they discard the packaging and bottles of pesticides after use right at the places where the pesticides were sprayed. This behavior is actually causing the environment in rural areas to degrade rapidly. In addition, the pesticides were abused that could lead to the accumulation of pesticides in the agricultural products. The study also found that there were $60 \%$ of the households uses pesticide dosage according to the instructions on the package or bottles; $26.7 \%$ of the households used more than recommended dosage and there were $13.3 \%$ the households used less than recommended dosage. The number of people with clear understanding of the harmful effects of plant protection chemicals accounted for $5.0 \%$, with knowledge accounting for $48.3 \%$, with little knowledge of $31.7 \%$ and with ignorance at $15 \%$.

The results of the interviews showed that the households accessing information on pesticides use via television and newspapers accounted for $11.7 \%$ and $15 \%$ respectively. Accessing to information through agricultural extension officers accounted for $33.3 \%$ and through 
pesticides dealers occupied $40 \%$. Besides, the rate of people accessing information through cooperatives in coordination with local authorities was $40.5 \%$. Thus, there are many information channels for people to learn about the use of pesticides. However, the majority of people use pesticides in the wrong way, at the wrong time. The purchase of pesticides is mainly based on advertising information from many small agents, so the origin and quality were not ensured. The use of labor protection in the pesticides spraying process is too sketchy, only using a mask during the spraying process. Up to $30 \%$ of interviewed people still eat and drink while spraying pesticides. The results implied that the use of pesticides by king orange growing farmers is highly risk to health and environment.

\section{CONCLUSION}

The findings of the present study showed that king orange growing model uses pesticides continuously from planting to harvest. The king orange farmers have used 6 pesticides with toxic group I; 53 pesticides with toxic group II; 22 pesticides with toxic group III and 40 pesticides with toxic group IV. There were $60 \%$ of the households uses pesticide dosage according to the instructions on the package or bottles; $26.7 \%$ of the households used more than recommended dosage and there were $13.3 \%$ the households used less than recommended dosage. The number of people with clear understanding of the harmful effects of plant protection chemicals accounted for $5.0 \%$, with knowledge accounting for $48.3 \%$, with little knowledge of $31.7 \%$ and ignorance at $15 \%$. Information on pesticides was accessed from television, newspapers, extension workers, plant protection agents, and the coordination between local authorities and cooperatives. Bottles and packages after use were treated by directly discharged at the fields $(45 \%)$, sold to the vendors $(30 \%)$, and burned (25\%). People only used masks when spraying pesticides and up to $30 \%$ of people interviewed eat and drink during the spraying process. The findings demonstrated that the current knowledge and practice of using and managing pesticides is not good. The risks to the environment and the health of the people caused by the pesticides are very serious. Local authorities need to take measures to raise qualifications and awareness of safe and sustainable use of pesticides in the study area.

\section{REFERENCES}

[1] Heong K L, Hardy B. Planthoppers: new threats to the sustainability of intensive rice production systems in Asia. Los Banos, Philippines: International Rice Research Institute (IRRI); 2009.
[2] Pham Manh Hoai, Sebesvari Z, Tu Binh Minh, Pham Hung Viet, Renaud F G. Pesticide pollution in agricultural areas of Northern Vietnam: Case study in Hoang Liet and Minh Dai communes. Environmental Pollution. 2011;159(12):3344-3350.

[3] Nguyen Van Cong, Nguyen Thanh Phuong, Bayley M. Brain cholinesterase response in the snakehead fish (Channa striata) after field exposure to diazinon. Ecotoxicology and Environmental Safety. 2008;71:314318.

[4] Bui Thi Nga and Lam Quoc Viet. Current status of production and residue of pesticides in soil and water on watercress (Nasturtium offocinale) in Thuan An commune, Binh Minh district, Vinh Long province. Scientific Journal of Can Tho University. 2010; 14: 278-287.

[5] Nguyen Duy Can and Vromant, N. PRA - Participatory Rural Assessment. Monographs, Agricultural Publishing House. TP. Ho Chi Minh City, 2009. 72 pages.

[6] Nguyen Dang Giang Chau, Le Dang Bao Chau and Le Thi Thanh Ngan. Knowledge, attitudes and practices in using pesticides of vegetable farmers in Thua Thien Hue province. Science Journal of Can Tho University. 2019; 55 (4B): 35-44

[7] Pham Van Toan. Current situation of pesticide use and a number of measures to minimize irrational drug use in rice production in the Mekong Delta. Can Tho University Journal of Science. Natural Science, Technology and Environment. 2011; 28: 47-53.

[8] Margni M, Rossier D, Crettaz P, Jolliet O. Life cycle impact assessment of pesticides on human health and ecosystems. Agriculture, Ecosystems and Environment. 2002;93(1-3):379-392.

[9] Nguyen Kim Binh. Surveying the current situation of pesticide use and proposing solutions to prevent and reduce pollution of surface water sources in the suburbs of Can Tho city. Graduate thesis; 2008.

[10] Nguyen Phan Nhan. Assessment of pesticide contamination in rice fields and main rivers and canals in Hau Giang province. Doctoral thesis of Can Tho University; 2018 